\title{
Treatment of second molar impaction
}

\author{
L. Messica
}

Dental surgeon, University Hospital consultant (Paris VII)

ABSTRACT

Although the prevalence of second molar impaction is not very high, retention can be a real functional problem within the oral cavity, leading to a loss of posterior support and decreased masticatory potential. Prevention and treatment may alleviate these problems. This article outlines the various treatment options and their implementation characteristics, to facilitate communication and the relationship between dental surgeon and orthodontist in implementing the chosen treatment plan.

\section{KEYWORDS}

Impaction, second molar, surgical exposure, surgical and orthodontic treatment

Tooth impaction is mainly due to eruption disorder, which may be local, general or iatrogenic ${ }^{2,4}$.

Although the concept of a "normal" eruption date is imprecise, certain studies have established mean ages with standard deviations for each tooth, deciduous or permanent. Management of impaction can thus be tailored to each case ${ }^{1,2,4}$.

Treatment strategy is guided by clinical and radiological examination, patient motivation and the practitioner's technical resources ${ }^{1,8}$.

Choice of procedure is to be decided jointly between dental surgeon and orthodontist.
Decision-making is based on several factors:

- patient age: impaction is treated if it is or is going to become symptomatic; prognosis is more favorable when there remains mandibular growth potential ${ }^{5}$;

- root shape and length: treatment will be more complicated when roots are divergent, hooked or particularly long7;

- root relationship with the basal edge of the mandible: when the root is within the basal edge of the mandible, a form of apical ankylosis of the tooth complicates traction ${ }^{3,4}$;

- degree of impaction: the deeper the tooth, the poorer the prognosis ${ }^{9,11}$;

- root apexification stage: if apical growth potential remains, treatment will be facilitated by natural root growth ${ }^{4,9}$.

Article received: 13-03-2015. 


\section{SURGERY $1,6,8,9,10,11$}

\section{Corticotomy, reimplantation}

Surgery sets the impacted tooth and the periodontal environment in a single step, after preparing sufficient space or extracting a premolar. The technique requires preoperative CT to assess the distance between the tooth/environment and adjacent structures (mandibular canal, adjacent roots). If adjacent structure lesions can be avoided, the procedure involves at least $2 \mathrm{~mm}$ of bone around the root and tooth in question.

\section{Alveolar conduction}

Alveolar conduction consists in removing a bone or mucosal obstacle by resecting the bone and gum between the crown and its physiological location in the arcade. The procedure is strictly mucosal when the bone level is below the maximum convexity of the crown. Gingivectomy should be performed within the attached gum, conserving the gingival ring of the adjacent teeth. When alveolectomy is associated, trauma should be minimized, using new burs on an instrument with strong torque, such as a surgical handpiece with spray, to avoid heating the bone. Alveolectomy should never extend beyond the crown and root (Fig. 1a, b, c).

\section{Dislocation}

Treatment consists in alveolar conduction associated to mild dislocation (by elevator or luxator) of the tooth, taking care to conserve the apical vascular-neural bundle to avoid ankylosis and promote eruption.
The technique requires the bone level of the tooth to be below the maximum convexity of the crown. Prognosis is best for teeth with a low Le Huche index, and straight convergent roots (Fig. 2a, b, c, d).

\section{Obstacle removal}

Second molar impaction may be due to tumor or to a malpositioned wisdom tooth. In the latter case, avulsion should be considered only with caution as, when second molar setting fails and requires extraction, positioning the wisdom tooth in 7 is an option of choice. In case of tumor, surgical resection of the obstacle allows the second molar to progress in the resulting space (Fig. 3a, b, c).

\section{Marsupialization}

Marsupialization consists in conserving the surgically created eruption pathway, avoiding formation of fibrous scar tissue by using:

- iodoform gauze packing;

- surgical cement.

In all such purely surgical treatment, great attention should be paid to periodontal health, as eruption potential must be conserved to avoid ankylosis by desmodontal lesion. The tooth must also progress surrounded by attached gum.

\section{Therapeutic abstention}

In case of deep impaction or impaction adjacent to structures such as the mandibular nerve, risk/benefit analysis may indicate abstention. This concerns most serendipitously detected impacted teeth. The dental surgeon should then perform annual check-ups 


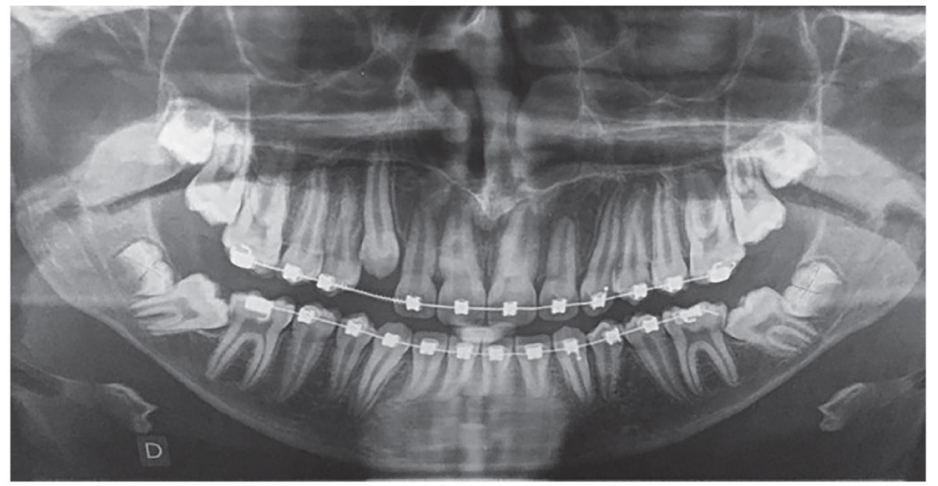

a

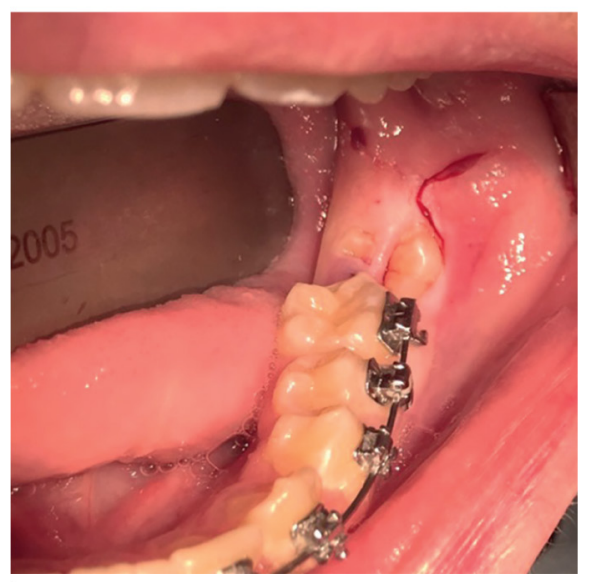

b

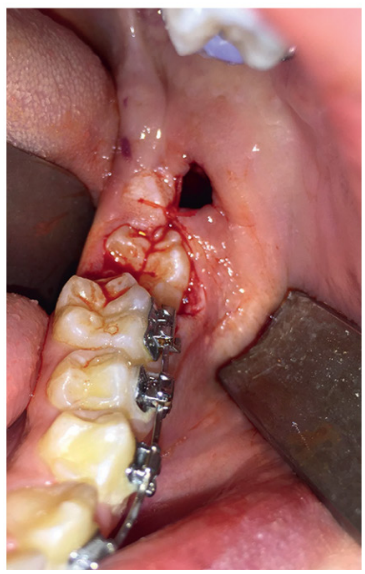

Figure 1

Case $n^{\circ}$ 1: a) Panoramic X-ray before treatment. b) Surgical site. c) Avulsion of 38, mucosal exposure of 37.

to monitor the critical region clinically (interview, palpation of any bone convexity, checking support tissue, visual aspect of gum around the site) and radiologically, with imaging to track the progression of the impacted tooth and thus detect any onset of radiolucency characterizing local infection.

\section{ORTHODONTIC/SURGICAL TREATMENT}

\section{Orthodontic/surgical exposure}

Successful orthodontic/surgical treatment requires the dental surgeon and orthodontist to work as a team, from the moment of diagnosis, with the objective of carrying out a complete treatment program.

Surgical exposure is performed after creating sufficient space for the impacted tooth to progress. 


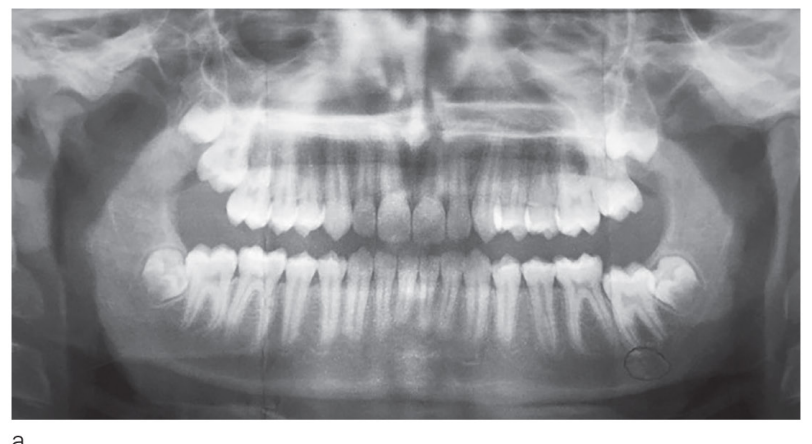

a
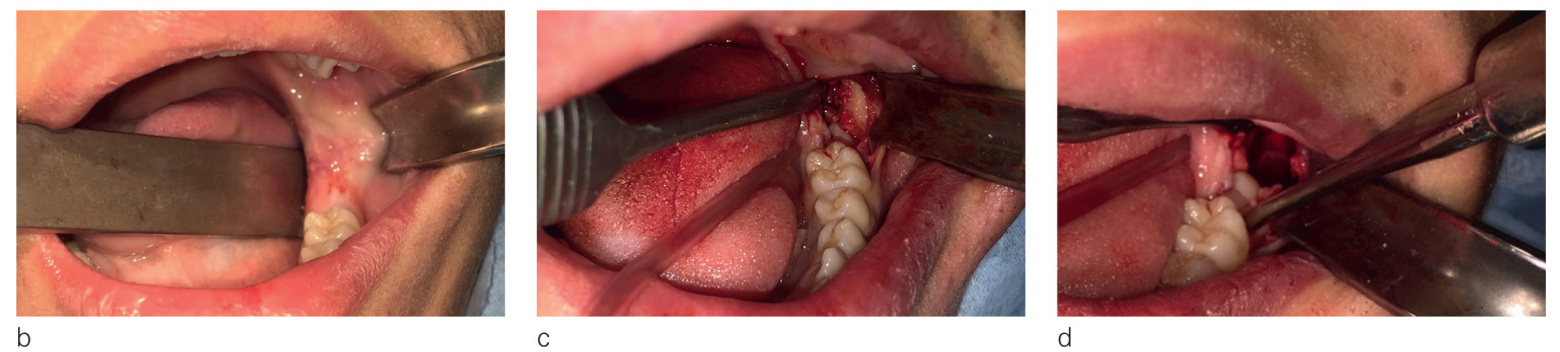

Figure 2

Case $n^{\circ}$ 2: a) Panoramic X-ray before treatment. b) Surgical site. c) Access flap. d) Avulsion of 38 and dislocation of 37.

The bone procedure should be minimal at the fixation point, which may be of the corkscrew, wing or button type. The glue used needs to have certain qualities:

- resistance to oral chemical and physicochemical aggression $(\mathrm{pH}$ and temperature variations);

- insolubility;

- good biocompatibility and bioactivity by release of bacteriostatic substances;
- immediate water-tightness, maintained over time to avoid patches of demineralization and decay;

- sufficient application time;

- easy removal of excess glue;

- easy bracket removal without damaging the enamel.

Composite glue with hydrophilic photopolymerizable adhesive provides the optimal combination of properties for orthodontic/surgical exposure.

\section{CLINICAL PROTOCOL}

\section{Enamel preparation}

- Cleaning: brushing and polishing.

- Mordanting by 35-37\% phosphoric acid for $30 \mathrm{sec}$, beyond the enamel surface to induce hemostasis of any soft tissue adjacent to the gluing region.

-5 sec rinse.

- Aspiration drying (never blowdrying, to avoid contaminating the 


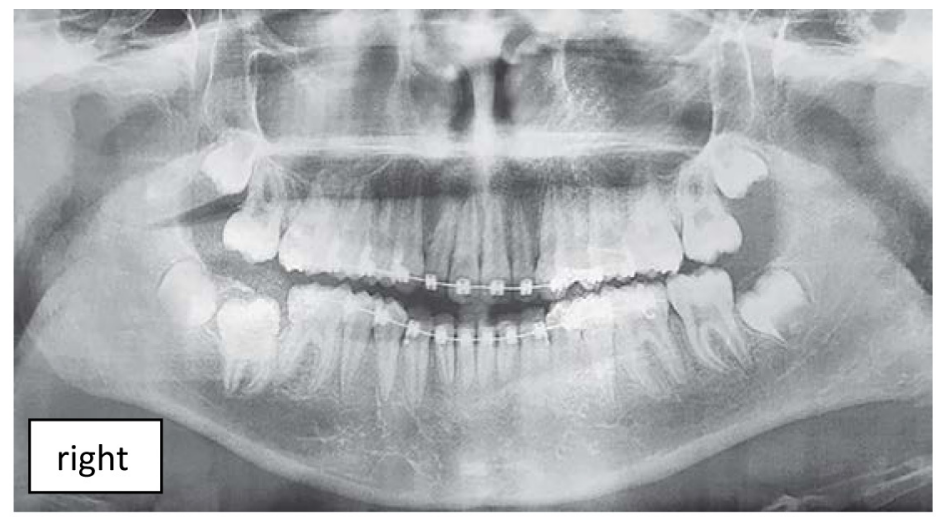

a
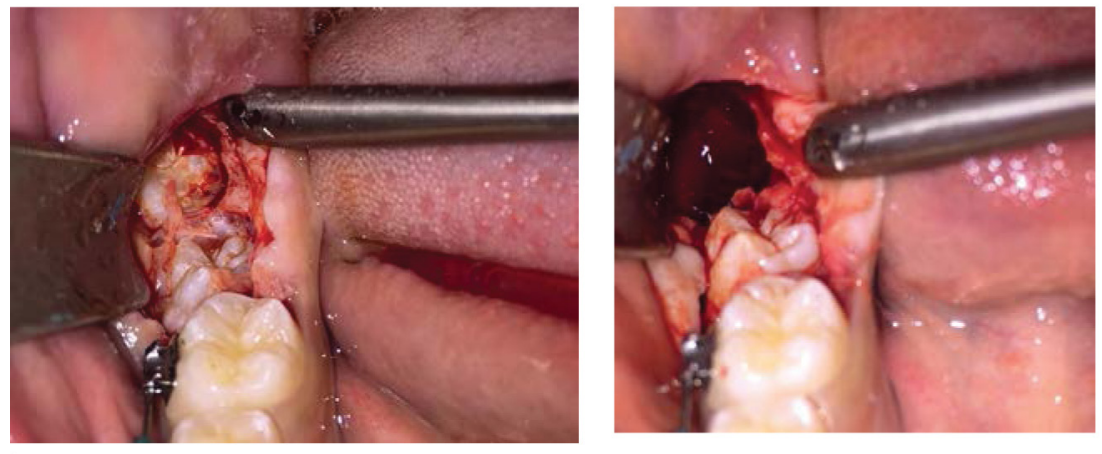

C

Figure 3

Case $n^{\circ}$ 3: a) Panoramic X-ray before treatment. b) Exposure of 47, 48. c) Avulsion of 48, setting 47 in arcade.

enamel surface with blood or saliva) until a chalky white aspect is obtained.

\section{Adhesive penetration}

In demineralized areas, penetration is badly impaired by humidity.

Any blood contamination requires

5 seconds' repeat mordanting.

\section{Gluing}

Gluing optimally requires three pairs of hands. An assistant keeps the enamel surface dry, with aspiration and distracter. The practitioner places a blob of composite on the bracket, held in place by automatic pliers directly on the surface for gluing and held firmly and immobile during positioning as centrally as possible on the side to be glued. Once this is in position, a second assistant brings a photopolymerization lamp as close as possible; a powerful lamp reduces polymerization time.

Some problems may arise during gluing: uncontrolled bleeding, difficulty of access, or difficulty of keeping the bracket immobile.

Once gluing has been completed under dry conditions, the traction resistance of the device has to be checked; the ligature between the 
bracket and the orthodontic apparatus may be in metal or elastomer (which shows poorer periodontal tolerance).

\section{CONCLUSION}

The patient should know the estimated treatment duration and risks. The decision should be informed, and the patient should be aware of alternatives, with their pros and cons, to ensure motivation and cooperation throughout treatment.

Progress in imaging, techniques, materials and awareness of the
The patient should quickly take an appointment with the orthodontist to activate the orthodontic traction apparatus.

periodontal environment has led to codified treatment strategies for impacted tooth traction. This multidisciplinary procedure now shows favorable prognosis, esthetically and functionally.

\section{Conflict of interest}

The author declares no conflicts of interest.

\section{REFERENCES}

1. Bakhoum A, Regragui S, Aalloula E. Les dents incluses en orthodontie : possibilités thérapeutiques. Le Chirurgien Dentiste, formation continue 2008;1371-1372:11/27.

2. Bassigny F. Manuel d'orthopédie dento-faciale. Éditions Masson, 1991.

3. Bassigny F. Ankylose, quand tu nous tiens ! Rev Orthop Dento Faciale 2007;41:321331.

4. Bondemark L, Tsiopa J. Prevalence of ectopic eruption, impaction, retention and agenesis of the permanent second molar. Angle Orthod 2007:773-778.

5. Capelli JR. Mandibular growth and third molar in extraction cases. Angle Orthod 1991;61(3):223-9.

6. Geiger AM, Bronsky MJ. Orthodontic management of ankylosed teeth. A clinical report of three cases. J Can Dent Assoc 2005;71(10):763-768.

7. Hazza'A AM, Albashaireh ZS, Bataineh A. The relationship of inferior dental canal to the roots of impacted mandibular third molars. J Comtemp Dent Pract 2006;7(2):71-8.

8. Johnson E. Managing second molars. Am J Orthod Dentofacial Orthop 2011:140(2):269273.

9. Magnusson $\mathrm{C}$, Kjellberg H. Impaction and retention of second molars: diagnosis, treatment and outcome. A retrospective follow-up study. Angle Orthod 2009:422-427.

10. Piette E, Reychler H. Traité de pathologie buccale et maxillo-faciale. De Boeck Université, 1991.

11. Raberin M. Inclusion des molaires: inquiétudes et réponses thérapeutiques. Rev Orthop Dento Faciale 2004;38:413-435. 